\title{
Phenotypic Variability of Dystrophinopathy Symptomatic Female Carriers
}

\author{
Ana Cotta, Julia Filardi Paim, Elmano Carvalho, Mônica Machado Navarro, \\ Jaquelin Valicek, Antonio Lopes da-Cunha-Junior, Miriam Melo Menezes, \\ Simone Vilela Nunes, Rafael Xavier-Neto, Eni Braga da Silveira, \\ Cynthia Costa-e-Silva, Reinaldo Issao Takata, Antonio Pedro Vargas
}

\begin{abstract}
Background: Dystrophinopathies are X-linked muscular dystrophies characterized by pathogenic mutations in the dystrophin gene. Symptomatic dystrophinopathy female carriers may present with limb-girdle weakness. The diagnosis may be challenging in the absence of affected male relatives. We aimed to describe the phenotypic variability in a series of molecular-confirmed female dystrophinopathy patients. Methods: This is a retrospective analysis of medical records from 1997 to 2015 . Results: Ten female dystrophinopathy patients were selected, two with unusual phenotypes: one with early joint contractures muscular dystrophy and the other with very late onset myopathy. Muscle imaging studies demonstrated predominant asymmetric fat replacement. Muscle biopsy immunohistochemistry demonstrated clear mosaic pattern in two cases and only subtle reduction of dystrophin intensity in three. Conclusions: Adequate diagnosis is fundamental for genetic counseling and cardiologic follow-up. Female patients with dystrophinopathy may present unusual phenotypes such as early contractures and very late onset myopathy.

RÉSUMÉ: Contexte: les dystrophinopathies sont des dystrophies musculaires liées au chromosome X, caracterisées par la mutation pathogénique du gène de la dystrophine. Les femmes porteurs symptomatiques de la dystrophinopathie peuvent présenter une perte de force musculaire proximale. Leur diagnostic peut être un défi en l'absence de membre de la famille de sexe masculin atteind de la dystrophinopathie. L'objectif est décrire la variabilité phénotypique chez une série des femmes atteind de la dystrophinopathie avec la confirmation moléculaire. Méthode: analyse rétrospective des dossiers médicaux depuis 1997 jusqu'a 2015. Résultats: dix femmes avec la dystrophinopathie ont été selectionnés: deux porteurs d’un phénotype atypique: une présentant une contracture articulaire précoce et l'autre une myopathie avec un début très tardif. Les examens d'imagerie de diagnostic des muscles ont démontrés la substitution fibroadipose prédominante asymétrique. L'analyse immunohistochimique de la dystrophine a demontré une claire mosaic chez deux patients et seulement une discrète réduction d'intensité de la dystrophine chez trois patients. Conclusions: le diagnostic adéquat est essentiel pour un conseil génétique et un suivit cardiologic. Les patients présentant une contracture précoce et une myopathie avec un début tardif peuvent être porteurs du phénotype de la dystrophinopathie.
\end{abstract}

Keywords: dystrophinopathy, symptomatic carrier, Xp21, contractures, imaging, rimmed vacuoles doi: $10.1017 / \operatorname{cjn} .2016 .448$

Can J Neurol Sci. 2017; 44: 304-310

Dystrophinopathies are a group of X-linked genetic diseases characterized by dystrophin gene mutations. They may be associated with various phenotypes including Duchenne and Becker muscular dystrophy, isolated quadriceps myopathy, asymptomatic or minimally symptomatic hyperCKemia, X-linked dilated cardiomyopathy, cognitive disorders, and symptomatic female carriers. ${ }^{1}$

Diagnosing symptomatic female carriers without affected male relatives may be challenging because these women's symptoms may simulate limb-girdle muscular dystrophy. ${ }^{2-5}$ The correct diagnosis is of utmost importance for adequate genetic counseling and cardiac follow-up.

\section{Patients And Methods}

A retrospective case series study of symptomatic dystrophinopathy carriers was conducted. Medical charts review was performed with evaluation of relevant clinical and serum muscle enzyme levels, imaging, muscle biopsy, and molecular studies. Data analysis was performed with approval of the institutional scientific and ethical committees.

Inclusion criterion was female patients with muscle weakness detectable in at least one muscle group with dystrophin gene

From the Departments of Pathology (AC, JFP), Neurophysiology (EC, JV), Pediatrics (MMN), Radiology (ALda-CJ), and Neurology (MMM, SVN, FX-N, APV), SARAH Network of Rehabilitation Hospitals, Belo Horizonte, Minas Gerais, Brazil; Departments of Electron Microscopy (EBS) Molecular Biology (CCeS, RIT), SARAH Network of Rehabilitation Hospitals, Brasília, Distrito Federal, Brazil.

Received August 5, 2016. Final Revisions Submitted October 7, 2016. Date of ACCEPTANCE NOVEMBER 20, 2016

Correspondence to: Ana Cotta, Rede SARAH de Hospitais de Reabilitação, Av.

Amazonas 5953, Gameleira, 30510-000, Belo Horizonte, MG, Brazil.

Email: ana_cotta@yahoo.com.br 
heterozygous mutation. ${ }^{3}$ Exclusion criteria were asymptomatic carriers and patients presenting with cramps, myalgia, exercise intolerance, or raised serum muscle enzyme levels without evidence of muscle weakness. ${ }^{3,6}$

Mutation (deletion or duplication) detection in the dystrophin gene was performed through the multiplex ligation-dependent probe amplification technique with SALSA P034 and SALSA P035 kits (MRC-Holland).

\section{RESULTS}

From 116 dystrophinopathy female carriers admitted from 1997 to 2015 in a neuromuscular reference clinic, $10(8.6 \%)$ symptomatic carriers were selected.

\section{Clinical Findings}

The clinical history from each patient is outlined in the following paragraphs and key clinical and laboratorial findings are summarized in Tables 1 and 2. Patient 1 was a 40-year-old woman that had started, at the age of 35, having frequent falls and progressive difficulty climbing stairs. Patient 2 was a 36 -year-old woman that reported that she did not speak until she was 4 years old and, at the age of 24, started having upper left arm weakness. Patient 3 was a 15-year-old girl that presented with frequent falls and difficulty walking and climbing stairs. Patient 4 was a 28-year-old woman that had started, in childhood, losing the incapacity to run and progressive difficulty climbing stairs. Patient 5 was a 26-year-old woman admitted with a history of elbow joint contractures since childhood, at age of 16 she started having difficulties raising from chairs, and at age of 18 started having myalgia, difficulties climbing stairs, and raising her arms. Patient 6 was a 68-year-old woman admitted with generalized myalgia and cramps since the age of 58; at age 63, she started having lumbar pain, frequent falls, and difficulties climbing stairs; she had dyslipidemia and had used statins for several years. Patient 7 was a 44-year-old woman with the inability to climb stairs without support since age 38 ; at age 44 , she started having difficulties raising her arms. Patient 8 was a 33 -year-old woman that had started, at the age of 12 , having a progressively abnormal gait, frequent falls, and difficulty standing up; at age 33, she started having difficulty climbing stairs and raising her arms. Patient 9 was a 48-year-old woman with abnormal, unstable gait and difficulty running and climbing stairs; at age 46, she began having frequent falls and difficulties raising her arms. Patient 10 was a 42-year-old woman that had acquired independent gait at the age of 3 , and, at the age of 28 , started progressive gait abnormality, cramps, and difficulty climbing stairs.

Five patients $(1,2,3,5$, and 6) were initially submitted for muscle biopsy with immunohistochemistry before subsequent molecular investigation. Five patients (4, 7-10) were not submitted for muscle biopsy and their diagnosis was confirmed by clinical, imaging, and molecular correlations.

Patients' ages at admission ranged from 15 to 68 years, with a mean of 38.1 years. The age range of first symptoms varied from the ages 2 to 58 , with a mean of 27.8 years (Table 1 ). Half of the patients did not present any affected male relatives (Table 1). Gowers maneuver was present in seven of eight patients, and patient 5 presented with early elbow contractures at initial clinical presentation (Table 1). Serum creatine kinase levels varied from 648 to $4509 \mathrm{IU} / \mathrm{l}$, which corresponded to a ratio of
3.9 to 27.3 times the respective reference values, with a mean increase of 9.7 times the reference values (Table 2). Creatine kinase levels are higher in younger patients than in older patients, when necrotic process of muscle fibers is active.

\section{Imaging Studies}

Patients 1, 3, 5, 7, and 8 underwent computed tomography scanning at the time of the investigation. Patient 6 underwent magnetic resonance imaging (MRI) on 1.5-Tesla equipment, including coronal and axial T1-weighted sequences, coronal and axial short $\mathrm{T} 1$ inversion recovery sequences, and axial fat-saturated T2-weighted sequences. Muscle imaging studies demonstrated predominant asymmetric muscle fat replacement (Figures 1 and 2, Table 2). Severe muscle fat replacement was observed as follows.

- Patient 1: bilateral medial, posterior, and anterior thigh; bilateral medial gastrocnemius; and left soleus

- Patient 3: bilateral glutei, bilateral adductor magnus, bilateral vastus intermedius, and left vastus lateralis

- Patient 5: right vastus lateralis, left quadriceps femoris, bilateral adductor magnus, bilateral biceps femoralis, left semimembranosus, bilateral soleus, bilateral peroneus, left gastrocnemius lateralis, and left gastrocnemius medialis

- Patient 6: right gluteus maximus, bilateral adductor magnus, bilateral semimembranosus, and right medial gastrocnemius

- Patient 7: right vastus lateralis, bilateral biceps femoris, right semitendinosus, right semimembranosus, bilateral adductor magnus, and left medial gastrocnemius

- Patient 8: bilateral vastus lateralis, bilateral vastus intermedius, left rectus femoralis, left biceps femoralis, left semitendinosus, left semimembranosus, bilateral soleus, left medial gastrocnemius, and right lateral gastrocnemius.

The most commonly involved muscle groups were glutei and thigh adductors, followed by posterior and anterior thigh and posterior leg muscles. Patients 1 and 8 presented the most severe muscle fat replacement, which corresponded to them having with the longest duration of symptoms: 14 and 21 years of disease progression, respectively (Figure 1, Table 2). All patients, except patient 1 , presented sartorius and gracilis muscles preservation compared with other muscle groups.

\section{Muscle Biopsy}

Muscle biopsy was performed in patients 1, 2, 3, 5, and 6 . A myopathic pattern was demonstrated in all patients, with a variation in fiber caliber. Immunohistochemical studies with serial sections with dystrophin-spectrin were performed, because spectrin is a marker of muscle fiber membrane integrity. Dystrophin immunohistochemistry demonstrated clear mosaic pattern in two patients ( 1 and 2 ) and only subtle reduction of dystrophin intensity in three patients $(3,5$, and 6) (Figure 3$)$. The intensity of dystrophin expression was compared with both preservation of spectrin expression in the same group of fibers in serial sections and intensity of dystrophin expression compared with normal fibers and control muscle (Figure 3).

\section{Molecular Studies}

All patients underwent molecular investigation and all presented dystrophin gene deletions (Table 2). The deletions were 
Table 1: Clinical presentation in a series of symptomatic dystrophinopathy carriers

\begin{tabular}{|c|c|c|c|c|c|c|c|c|c|}
\hline Patient & $\begin{array}{c}\text { Age } \\
\text { (years) }\end{array}$ & $\begin{array}{c}\text { Start } \\
\text { (years) }\end{array}$ & Affected relatives & First clinical presentation & $\begin{array}{l}\text { Age (years) and status at last } \\
\text { evaluation }\end{array}$ & Calf & Gowers & Contractures & Other clinical findings \\
\hline 1 & 40 & 35 & $\begin{array}{l}\text { Three stillborn } \\
\text { siblings }\end{array}$ & Difficulty climbing stairs & 52: walk with support & + & + & - & - \\
\hline 2 & 36 & 24 & Son & Weakness in left upper limb & 37: independent gait & + & + & - & Winged scapula \\
\hline 3 & 15 & 15 & Absent & Frequent falls & 18: independent gait & + & + & - & Winged scapula \\
\hline 4 & 28 & 6 & Son & Difficulty running and climbing stairs & 28: independent gait & NA & + & - & Generalized muscle weakness \\
\hline 5 & 26 & 16 & Absent & Elbow contractures & 27: independent gait & + & - & $\begin{array}{l}\text { Elbows } \\
\quad \text { (early) }\end{array}$ & Scapular weakness \\
\hline 6 & 68 & 58 & Absent & Myalgia, frequent falls & 69: independent gait & + & - & - & $\begin{array}{l}\text { Biceps brachialis, thumb adductors, and } \\
\text { right thigh atrophy }\end{array}$ \\
\hline 7 & 44 & 38 & Absent & Difficulty climbing stairs & 45: independent gait & + & + & - & Normal reflexes \\
\hline 8 & 33 & 12 & Absent & Left lower limb limp & 33: walk with support & + & NR & - & Limited feet dorsiflexion \\
\hline 9 & 48 & 46 & $\begin{array}{l}\text { Nephew and grand- } \\
\text { nephew }\end{array}$ & $\begin{array}{l}\text { Abnormal instable gait, difficulty running } \\
\text { and climbing stairs }\end{array}$ & 48: independent gait & + & + & - & Scapular and pelvic atrophy \\
\hline 10 & 42 & 28 & $\begin{array}{l}\text { Four brothers and one } \\
\text { nephew }\end{array}$ & Abnormal gait & 42: independent gait & + & NR & - & Lower limb cramps \\
\hline
\end{tabular}

Age $=$ age at admission; calf $(+)=$ increased calf volume; $\mathrm{NA}=$ not available; NR = not reported; start: age at first symptoms.

\section{Table 2: Ancillary investigation in a series of symptomatic dystrophinopathy carriers}

\begin{tabular}{|c|c|c|c|c|c|}
\hline Patient & Cardiac status & $\begin{array}{l}\text { Serum creatine kinase in IU/l } \\
\text { (increase) }\end{array}$ & $\begin{array}{l}\text { Muscle biopsy dystrophin } \\
\text { immunohistochemistry }\end{array}$ & $\begin{array}{l}\text { Imaging age } \\
\text { (evolution) }\end{array}$ & DMD gene mutation \\
\hline 1 & Extrasystoles & $648(3.9 \times)$ & Mosaic with totally negative fibers & $49(14)$ & Heterozygous deletion, exons $20-41$, out of frame \\
\hline 2 & Normal electrocardiogram & $1862(11.2 \times)$ & Mosaic with totally negative fibers & NA & Heterozygous deletion, exon 45 , out of frame \\
\hline 3 & Mitral valve prolapse & $4509(27.3 \times)$ & $\begin{array}{l}\text { Mosaic with reduced intensity and rare } \\
\text { negative fibers }\end{array}$ & $17(16)$ & $\begin{array}{l}\text { Heterozygous c. } 1554 \mathrm{~T}>\mathrm{A} \text {, p.D518E missense } \\
\text { mutation in exon } 13\end{array}$ \\
\hline 4 & NR & $1559(9.4 \times)$ & NA & NA & Heterozygous deletion, exons $46-55$, out of frame \\
\hline 5 & Normal electrocardiogram and echocardiogram & $947(5.7 \times)$ & $\begin{array}{l}\text { Mosaic with reduced intensity and uneven } \\
\text { reaction }\end{array}$ & $26(10)$ & Heterozygous deletion, exons $38-43$, out of frame \\
\hline 6 & Left ventricle overload & $808(4.8 \times)$ & $\begin{array}{l}\text { Mosaic with reduced intensity and rare } \\
\text { negative fibers }\end{array}$ & $68(10)$ & Heterozygous deletion, exons 45 and 46 , in-frame \\
\hline 7 & Left ventricle overload & $1845(11.1 \times)$ & NA & $44(6)$ & Heterozygous deletion, exons 20 to 29 , in-frame \\
\hline 8 & $\begin{array}{l}\text { Sinusal tachycardia and inferior wall repolarization } \\
\text { abnormalities }\end{array}$ & $1886(11.4 \times)$ & NA & $33(21)$ & Heterozygous deletion, exons 13-17, out-of-frame \\
\hline 9 & Right branch and anterosuperior left branch block & $783(4.7 \times)$ & NA & NA & Heterozygous deletion, exons $48-50$, out-of-frame \\
\hline 10 & Abnormal left ventricle diastolic relaxation & $1241(7.5 \times)$ & NA & NA & Heterozygous deletion, exons 47 and 48 , in-frame \\
\hline
\end{tabular}

Serum creatine kinase times increase referent to each age-dependent reference values.

Imaging age $=$ age at image studies and time elapsed between first symptoms and imaging examination; mosaic $=$ dystrophin immunohistochemistry with positive and negative or decreased intensity fibers; NR = not reported. 

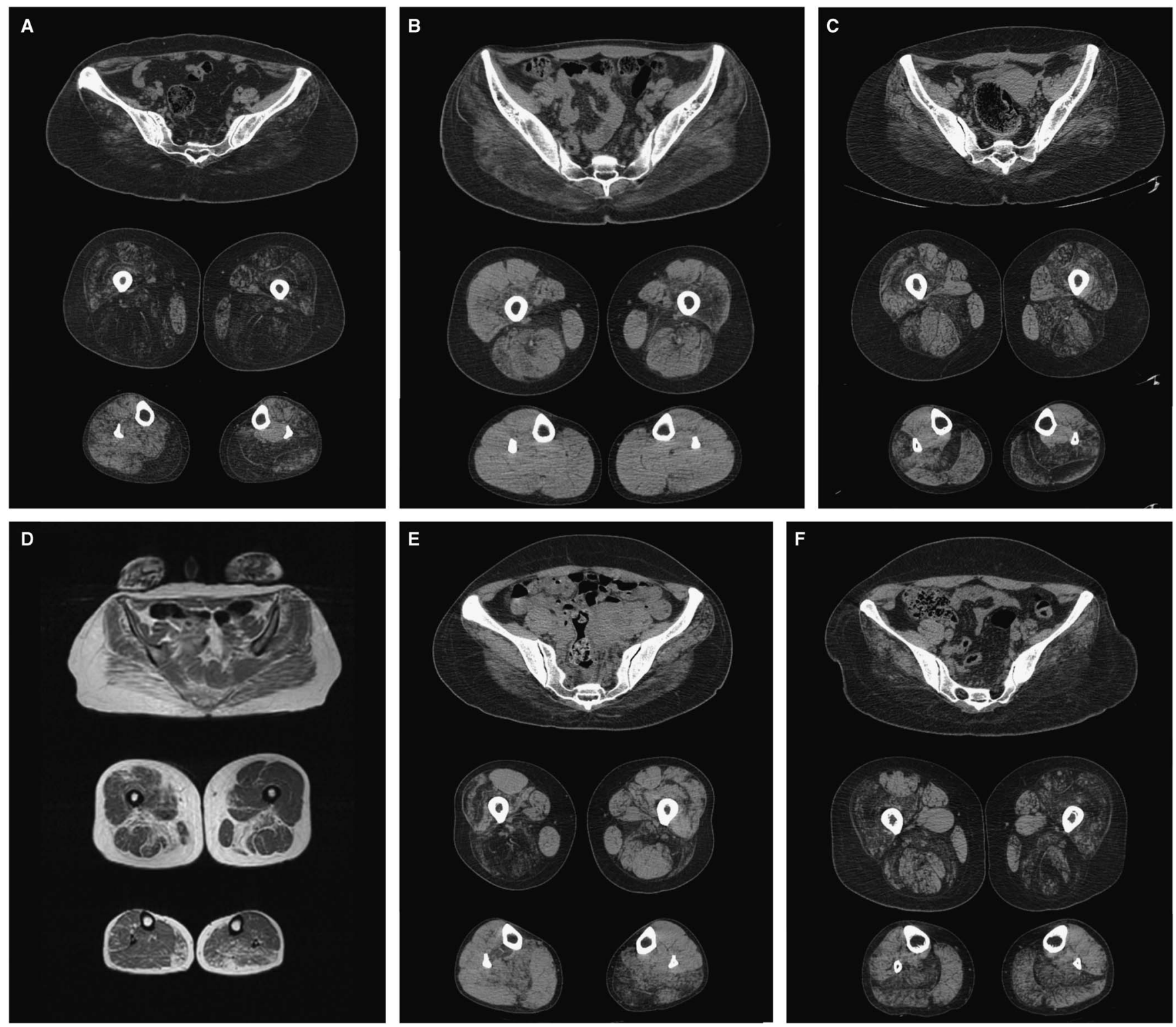

Figure 1: Muscle image studies: predominant asymmetric muscle fat replacement of pelvis, thigh, and legs. (A) Patient 1 CT, (B) patient 3 CT, $(C)$ patient $5 C T,(D)$ patient 6 magnetic resonance imaging, $(E)$ patient $7 C T$, and $(F)$ patient $8 C T$.

found in DMD gene exons $13,13-17,20-29,20-41,38-43,45$, $45-46,46-55,47-48$, and 48-50 (Table 2). Heterozygous c.1554T > A, p.D518E missense mutation in exon 13, to the best of our knowledge, has not been previously described. This mutation was associated with immunohistochemical dystrophin mosaic pattern and considered functionally pathogenic (patient 3 )(Table 2).

\section{DISCUSSION}

The majority of dystrophin female carriers are asymptomatic. The frequency of symptomatic carriers found in this study was $8.6 \%$. These data are in accordance with previous studies that describe ratios from $2.5 \%$ to $17 \% .^{3,7}$ There is clinical overlap between symptomatic female carriers with dystrophinopathy and limb-girdle muscular dystrophy. ${ }^{2-6}$ The differential diagnosis between both is of the utmost importance for adequate genetic counseling because limb-girdle muscular dystrophy presents with dominant or recessive autosomal inheritance and dystrophinopathy presents an X-linked inheritance.

In an UK epidemiological study, the prevalence of symptomatic female carriers was 0.43 per 100,000 inhabitants (from a total of 8.46 per 100,000 symptomatic dystrophinopathy men and women). ${ }^{8}$ The prevalence of symptomatic female carriers was similar to the prevalence of the most common limb-girdle muscular dystrophies, such as fukutin-related proteinopathy (LGMD2I) with 0.43 per 100,000 inhabitants and calpainopathy (LGMD2A) with 0.60 per 100,000 inhabitants. ${ }^{8-10}$

Symptomatic female dystrophin carriers may present asymmetric lower limb muscular weakness that may be slight or as severe as rapidly progressive Duchenne-like muscular dystrophy. ${ }^{3}$ 


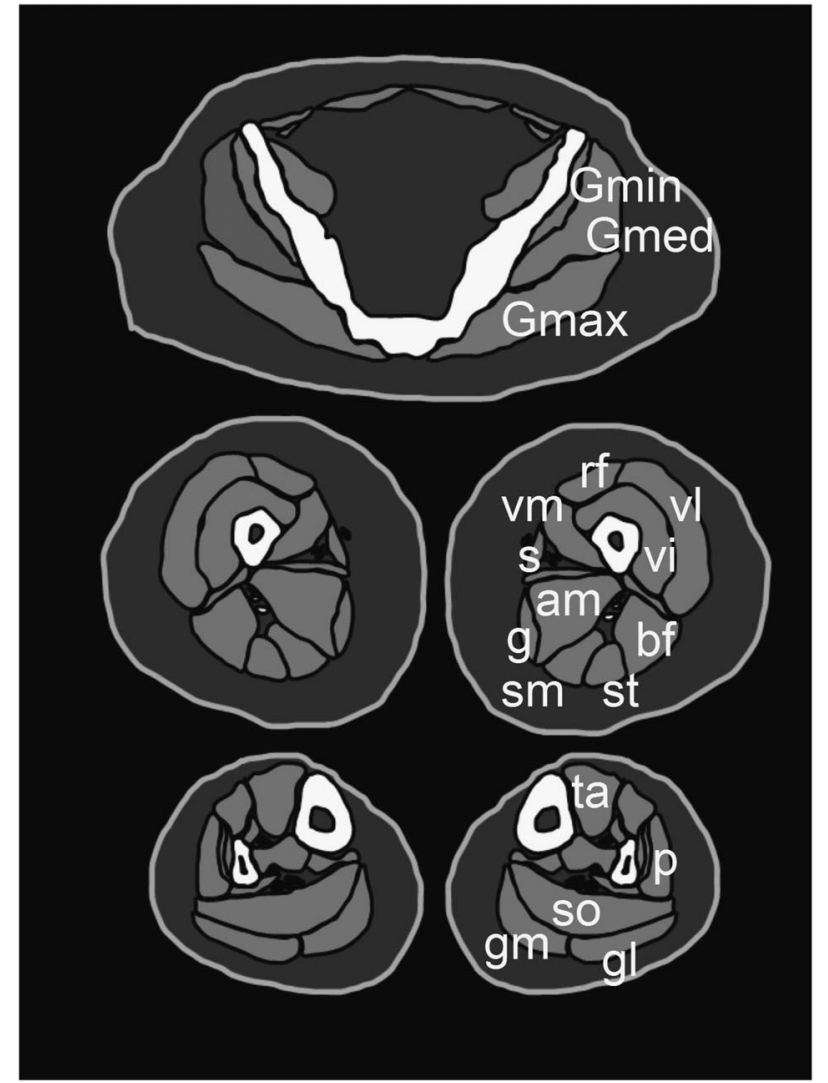

Figure 2: Schematic diagram of the pelvis, thighs, and legs. am=adductor magnus; bf=biceps femoris; $g=$ gracilis; $g l=$ gastrocnemius lateralis; gm = gastrocnemius medialis; Gmax = gluteus maximus; Gmed $=$ gluteus medius; Gmin=gluteus minimus; $p=$ peroneus; $r f=$ rectus femoris; $s=$ sartorius $; \quad s m=$ semimembranosus $; \quad$ so $=$ soleus $; \quad$ st $=$ semitendinosus; ta $=$ tibialis anterior; $v i=v a s t u s$ intermedius; $v l=v a s t u s$ lateralis, $v m=$ vastus medialis.

Patient 6 presented with a late-onset muscular weakness that was noticed after dyslipidemia treatment and the hypotheses of statin-induced myopathy had been raised. The detection of asymmetric muscular weakness with right quadriceps femoris atrophy, increased creatine kinase levels, and a mixed electromyogram pattern raised the diagnostic hypotheses of muscular dystrophy or sporadic inclusion body myositis. Her muscle biopsy demonstrated one rimmed vacuole, myofibrillar disorganization, and 12- to 18-nm filamentous inclusions (Figure 3).

Rimmed vacuoles have been previously described in a dystrophinopathy patient with Becker phenotype without calf volume increase and with dystrophin gene deletion. ${ }^{11}$ In that study, transmission electron microscopy demonstrated autophagic vacuoles but no filamentous inclusions were detected. ${ }^{11}$

It is not clear if the filamentous inclusion observed in patient 6's muscle biopsy may be attributed to an unusual phenotype of symptomatic female carrier of dystrophinopathy or to a superposition of sporadic inclusion body myositis (double trouble). Even though some characteristics of sporadic inclusion body myositis were lacking, such as no finger flexors weakness compared with deltoideus muscle weakness, iliopsoas muscle weakness was worse than quadriceps femoris weakness and no lymphocytic inflammatory infiltrate was observed. ${ }^{12}$
The autophagic vacuoles found may be secondary lysosomes that resulted from sublethal muscle fiber lesions. ${ }^{11}$ No myofibrillar deposits were observed on patient 6's muscle biopsy. The correct diagnosis of this patient was of utmost importance for genetic counseling of her children. No well-defined increased signal areas on short $\mathrm{T} 1$ inversion recovery sequences that could suggest edema and favor the diagnosis of sporadic inclusion body myositis were found on her muscle magnetic resonance imaging studies. Immunohistochemistry for MHC-1 was performed and no increased sarcolemmal reaction was observed; vessel MHC-1 reaction similar to the normal control was observed (Figure 4).

Muscle imaging studies presented as common characteristics: asymmetric muscle fat replacement in the thighs and legs, especially the posterior thigh and medial gastrocnemius with relative preservation of sartorius and gracilis as previously described (Figure 1). ${ }^{5}$ Multiplex ligation-dependent probe amplification genetic analysis is not performed on a routine basis for all patients, but all muscle biopsy candidates undergo muscle imaging studies. Before any muscle biopsy, the neuromuscular clinic's neurologists, neurophysiologists, pediatricians, radiologists, and pathologists review all noninvasive procedures that could be performed to elucidate the diagnosis. Diagnostic hypotheses are raised based on imaging studies in conjunction with clinical and laboratorial data. Patients 7 and 8 presented limb-girdle muscular weakness, pronounced calf pseudohypertrophy, increased muscle enzymes, and imaging studies that demonstrated asymmetric involvement with muscle fat replacement of the gluteus maximus and medius, biceps femoris, adductor magnus, and vasti as well as no muscle involvement of the sartorius and gracilis, consistent with the descriptions by Tasca et al. ${ }^{5}$

Duchenne muscular dystrophy, in male patients, usually presents widespread dystrophic pattern of fibroadipose replacement of the muscle tissue with numerous fibers with necrosis and phagocytosis. On the contrary, symptomatic female carriers may present a myopathic pattern only, with variation in fiber caliber and sparse necrosis and phagocytosis foci (Figure 3). A high suspicion level is necessary for the diagnosis; systematic performance of dystrophin immunohistochemical studies has been recommended by some authors. ${ }^{4}$ Besides that, a secondary sarcoglycan deficiency may be observed in patients with dystrophin gene abnormalities. ${ }^{13,14}$

Joint contractures are common late findings in advanced stages of dystrophinopathy; early joint contractures as the first clinical presentation of dystrophinopathy, as observed in patient 5, are not expected (Table 1). Early contractures had been previously described in males with dystrophinopathy, but this may be the first description of early contractures in a symptomatic female carrier. $^{4}$

\section{Conclusions}

Absent familial history of affected male relatives, early elbow contractures, and very late onset myopathy may occur in female carriers of dystrophinopathy. One novel dystrophin gene point mutation was described: heterozygous c.1554T $>$ A p.D518E missense mutation considered pathogenic because it was observed in a patient with immunohistochemical dystrophin mosaic pattern.

The differential diagnosis between symptomatic female carriers with dystrophinopathy and limb-girdle muscular dystrophy is of utmost importance for adequate genetic counseling and cardiological follow-up. 

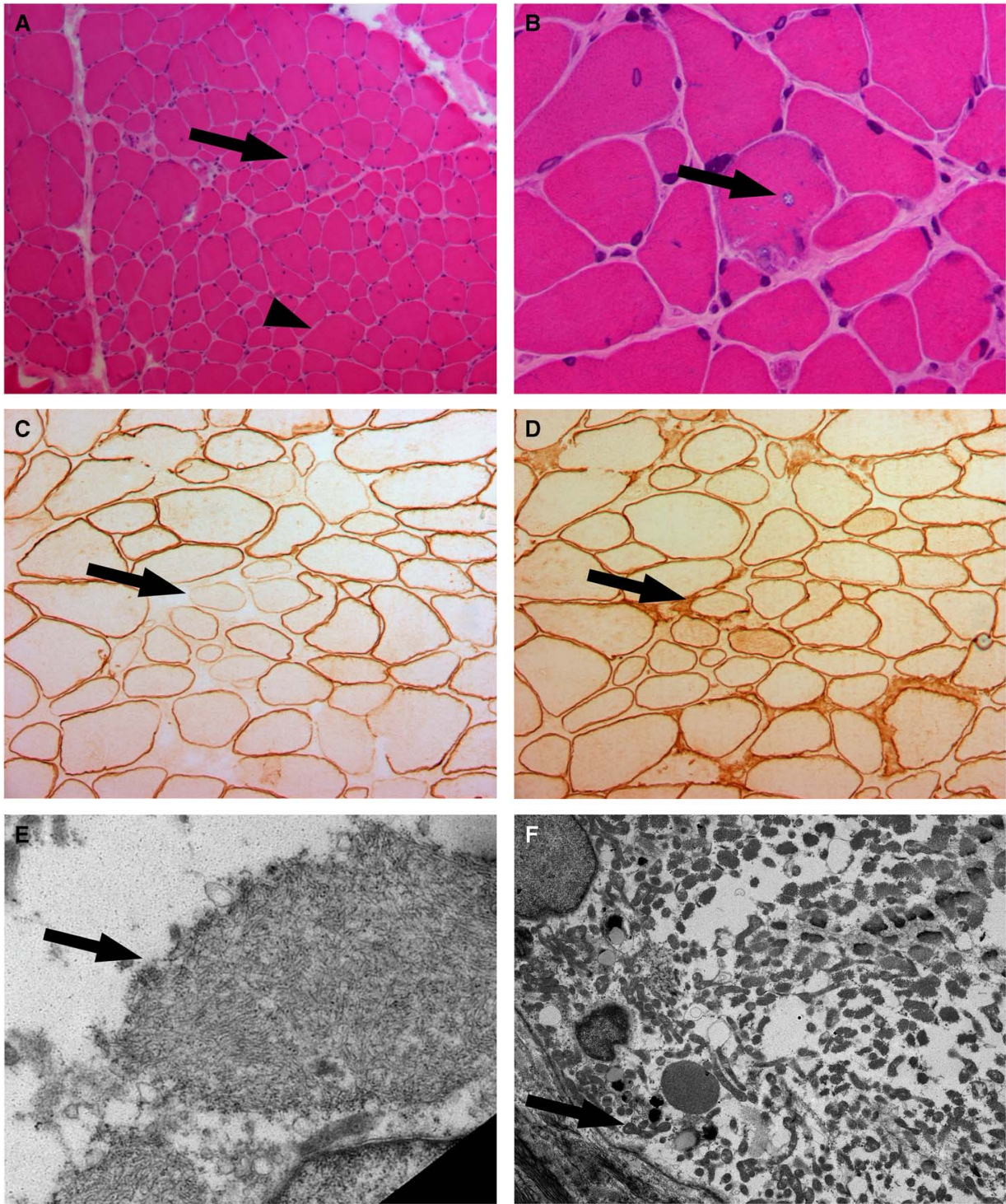

Figure 3: Muscle biopsy of patient 6. (A) Variation in fiber caliber with atrophy (arrow) and hypertrophy (arrow head) (hematoxylin and eosin [HE], 100×). (B) Rimmed vacuole (arrow) $(H E 400 \times)$ ). (C, D) Serial sections (arrows) of muscle fibers with decreased dystrophin immunohistochemical expression and preservation of spectrin expression. (C) dystrophin carboxy terminal DYS2 $200 \times ;(D)$ spectrin $200 \times$ ). (E) Filamentous inclusions (arrow). (F) Myofibrillar loss and accumulation of dense matrix mitochondria (arrow). (E, F) Transmission electron microscopy 15,000 $\times, 6000 \times$.
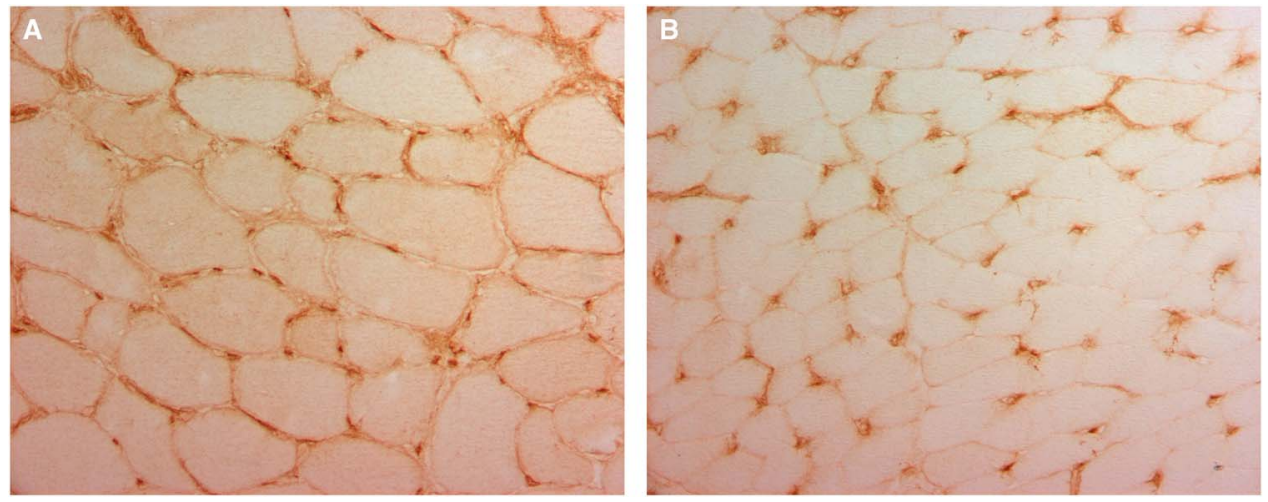

Figure 4: (A) Absent sarcolemmal MHC-1 reaction in patient 6. (B) Control with absent sarcolemmal reaction and normal vessel reaction (immunohistochemistry MHC-1). 


\section{ACKNOWLEDGMENTS}

The authors thank the families for their participation in the study. We thank Cleides Campos de Oliveira and Simone Ferreira do Nascimento for technical assistance.

\section{Disclosures}

The authors declare that they have no conflicts of interest.

\section{STATEMENT OF AUTHORSHIP}

MMN, MMM, SVN, RXN, and APV performed the clinical diagnoses, collected the patients' clinical data, and revised the manuscript. JV and EC were involved in analysis and interpretation of neurophysiological studies and revising the manuscript. CCS and RYT undertook the molecular investigation, were involved in interpretation of molecular data, and revising the manuscript. ALda-CJ was involved in the acquisition and interpretation of data regarding muscle image studies and revising the manuscript. EBS was involved in interpreting electron microscopy studies and revising the manuscript. AC and JFP were involved in conducting muscle biopsy studies, interpreting muscle biopsy results, and revising the manuscript. AC was involved in the conception, design, and drafting and revision of the manuscript. All authors read and approved the final manuscript.

\section{REFERENCES}

1. Wicklund MP. The muscular dystrophies. Continuum (Minneap Minn). 2013;19:1535-70.

2. Golla S, Agadi S, Burns DK, et al. Dystrophinopathy in girls with limb girdle muscular dystrophy phenotype. J Clin Neuromuscul Dis. 2010;11:203-8.
3. Soltanzadeh P, Friez MJ, Dunn D, et al. Clinical and genetic characterization of manifesting carriers of DMD mutations. Neuromuscul Disord. 2010;20:499-504.

4. Doriguzzi C, Palmucci L, Mongini T, Chiadó-Piat K, Maniscalco M, Restagno G. Systematic use of dystrophin testing in muscle biopsies: results in 201 cases. Eur J Clin Invest. 1997;27: 352-358.

5. Tasca G, Monforte M, Iannaccone E, et al. Muscle MRI in female carriers of dystrophinopathy. Eur J Neurol. 2012;19: $1256-1260$

6. Lee SH, Lee JH, Lee KA, Choi YC. Clinical and genetic characterization of female dystrophinopathy. J Clin Neurol. 2015;11: 248-251.

7. Heide S, Afenjar A, Edery P, et al. Xp21 deletion in female patients with intellectual disability: Two new cases and a review of the literature. Eur J Med Genet. 2015;58:341-5.

8. Norwood FL, Harling C, Chinnery PF, Eagle M, Bushby K, Straub V. Prevalence of genetic muscle disease in Northern England: in-depth analysis of a muscle clinic population. Brain. 2009; 132:3175-3186.

9. Zatz M, de Paula F, Starling A, Vainzof M. The 10 autosomal recessive limb-girdle muscular dystrophies. Neuromuscul Disord. 2003;13:532-44.

10. Albuquerque MA, Abath Neto O, Silva FM, Zanoteli E, Reed UC. Limb-girdle muscular dystrophy type $2 \mathrm{~A}$ in Brazilian children. Arq Neuropsiquiatr. 2015;73:993-7.

11. de Visser M, Bakker E, Defesche JC, Bolhuis PA, van Ommen GJ. An unusual variant of Becker muscular dystrophy. Ann Neurol. 1990;27:578-81.

12. Rose MR, ENMC IBM Working Group. 188th ENMC International Workshop: Inclusion Body Myositis, 2-4 December 2011, Naarden, The Netherlands. Neuromuscul Disord. 2013;23: 1044-1055.

13. Draviam R, Billington L, Senchak A, Hoffman EP, Watkins SC. Confocal analysis of the dystrophin protein complex in muscular dystrophy. Muscle Nerve. 2001;24:262-72.

14. Engel AG, Franzini-Armstrong C. editors Myology, 3rd ed. New York: McGraw-Hill; 2004, p. 1-1960. 